\title{
Multiple goals and ownership structure: Effects on the performance of Spanish savings banks
}

\author{
Miguel García-Cestona ${ }^{\mathrm{a}, *}$, Jordi Surroca ${ }^{\mathrm{b}} \equiv$ \\ a Department of Business Economics, Universitat Autònoma de Barcelona, 08193 Bellaterra (Barcelona), Spain \\ ${ }^{\mathrm{b}}$ Department of Business Administration, Universidad Carlos III de Madrid, 28903 Getafe (Madrid), Spain
}

\begin{abstract}
Spanish savings banks (SBs) are financial institutions with a wide mission that includes different stakeholders' goals. Profit maximization is only one among several goals, and the widespread use of cost or profit efficiency as the only comparative performance measure may prove to be insufficient in this context. To overcome this problem, we build an aggregate performance index for organizations with multiple goals. Furthermore, we show how the ownership structure of SBs influences their economic behavior in two basic ways: (1) the performance level and (2) their goal priorities. In particular, we distinguish two types of ownership structures in our application, namely, organizations controlled by Public Administrations and those controlled by insiders (i.e. managers and workers). Our results indicate that each type has different priorities and differ in their performance indexes. More specifically, the empirical analysis shows that insider-controlled SBs favor goals related to profit maximization and the universal access to financial services and, furthermore, they perform better. In contrast, contributing to regional development becomes the most favored goal when Public Administrations have a majority in the bank.
\end{abstract}

Keywords: Data envelopment analysis (DEA); DEA weights; OR in banking; Ownership structure; Productivity and competitiveness

\section{Introduction}

In this paper, we examine the relationships between regulation, ownership structure and eco nomic behavior of Spanish savings banks (SBs) dur ing the period 1998 2002. The three objectives we aim to cover are: (1) an assessment of how regula tion affects the ownership structure and the objec

\footnotetext{
${ }^{*}$ Corresponding author. Tel.: +34 935812147.

E-mail addresses: cestona@selene.uab.es (M. García-Cestona), jsurroca@emp.uc3m.es (J. Surroca).
}

tive function of Spanish savings banks, (2) an analysis of the efficiency levels and goal priorities of these financial institutions, and (3) an evaluation of regulation efficiency. To achieve these objectives, we employ existing methodological developments in the area of data envelopment analysis (DEA).

Our analysis is related to two different strands in the literature on frontier efficiency analysis: one focuses on the link between banks organizational forms and frontier efficiency, while the other studies value judgments in DEA models. Within the first strand, substantial research effort has gone into 
answering the question of whether bank ownership influences economic behavior (Berger and Hum phrey, 1997). In particular, previous studies have examined the differential effect on efficiency of mutual versus stock owned banks (Cebenoyan et al., 1993; Mester, 1993; Altunbas et al., 2001), banks with stocks traded on capital markets versus private banks (Tulkens, 1993), government owner ship versus private banks (Altunbas et al., 2001), foreign versus domestic banks (Chang et al., 1998; Bhattacharya et al., 1997; Fukuyama et al., 1999; Sathye, 2001), minority versus non minority owned banks (Elyasiani and Mehdian, 1992), and small versus large banks (Elyasiani and Mehdian, 1995), among others. Concerning the Spanish banking industry, there are several studies (Grifell Tatjé and Lovell, 1997; Tortosa Ausina, 2003) that have assessed the efficiency of savings banks and com mercial banks, postulating whether the differences in ownership between these organizational forms may lead to different efficiency levels.

One potential drawback of most applications in this area has been the lack of the behavioral objec tives of each organizational type at the time of com puting efficiency. The measurement of performance becomes a function of how well an organization achieves its objectives (Piesse and Townsend, 1995), and in many of the previously mentioned comparisons between organizational forms the equality of objectives cannot be taken for granted. For example, when comparing mutual banks with other organizational forms, one should take into account the complexity of the behavioral objectives of these institutions (Worthington, 2004) objec tives that are more closely related to the maximiza tion of the services provided to members (Fried et al., 1993). Therefore, profit maximization does not seem the most appropriate goal for measuring the performance of mutual banks. Similarly, the organizations we are interested in Spanish savings banks pursue, by law, a wide set of goals. Further more, given the absence of shareholders, making a profit becomes only one among several measures of success. Due to the fact that the control of SBs has been allocated, also by law, to several types of stakeholders, each one with different interests, SBs try to demonstrate that they are well managed, peo ple oriented, accessible to the individual, friendly to the small investor, and in touch with the local com munity (Serrano Cinca et al., 2004). Therefore, to measure their performance, we need to go beyond traditional efficiency indicators and look further into the way they create value for their stake holders.

Until now, however, a common feature of all papers that evaluate the efficiency of Spanish sav ings banks is the use of the very same indicators analyzed in commercial banks. That is, by means of productivity (Grifell Tatjé and Lovell, 1997; Pas tor, 1995), costs (Lozano Vivas, 1998; Maudos et al., 2002; Maudos and Pastor, 2003; Tortosa Ausina, 2003) or profits (Kumbhakar et al., 2001; Lozano Vivas, 1997). Thus, previous studies have all omitted the multiple goal nature of SBs, which renders the use of only costs or profits inadequate as a way of measuring managers' efficiency.

As mentioned above, this paper is also inspired by the literature on weight restrictions in DEA. As discussed in the comprehensive review by Allen et al. (1997), the most widespread method for con sidering judgments or preferences in DEA models is the use of restrictions on weights. These restric tions are imposed in an attempt to incorporate the decision maker's preferences into the assessment of efficiency. Typically, the value preferences included in previous studies reflected either top manage ment's or the researchers' views on the relative importance of inputs and outputs. To the best of our knowledge, only two studies (Thanassoulis, 2000; Lins et al., 2007) have considered the regula tor as a key actor whose preferences must be incor porated in the assessments. In this study, we focus on another kind of regulation: the regulation affect ing the ownership structure of organizations. More specifically, we assume that regulator preferences on outputs are expressed by means of the voting distri bution in the governing bodies of an organization.

In this paper, data envelopment analysis methods are used to elaborate an aggregate performance index that combines multiple goals where profit maximization is one among several goals and it also calculates the relative importance of each goal. Some idiosyncratic features make this methodology specially suitable in this context: DEA is quite effec tive in handling complex processes of organizations that do not behave like traditional firms, but use multiple inputs to produce multiple outputs, or when the weights (i.e., the relative importance) attached to each input/output are unknown. Several authors have acknowledged the potential of DEA methodology to assess the performance of those organizations that violate the behavioral assump tions under which commercial banks operate. Spanish savings banks constitute one of these 
organizations and credit unions provide another example. Regarding this later type of organizations, Fried et al. (1993, p. 253) argued, "since credit unions are owned and operated by members, the objectives of credit unions can be thought of as maximizing the services provided to members. This immediately suggests that profit maximization is not the most appropriate objective". Therefore, in sev eral empirical works measuring the efficiency of financial mutual organizations, profit maximization is not assumed: Mester (1993) for savings and loans in the US, Fried et al. (1993) for credit unions in the US, Piesse and Townsend (1995) for British building societies, or Worthington $(1998,2004)$ with credit unions in Australia.

We use the above methodological proposal in comparing efficiency under multiple goals in the case of Spanish savings banks. We consider the existing agency relationship between the executive managers of the savings bank (the agents) and the legislator (the principal), who establishes a wide mission for the bank. Accordingly, a savings bank's manager should replace the profit maximization goal with the maximization of the aggregated goals included in the mission. Yet, agents have their own prefer ences on how to combine those multiple goals, and these are not always coincident with the legislator's. Thus, our measure of performance incorporates this multiplicity of goals and, subsequently, it includes legislator preferences on those multiple goals. Fur thermore, we assume these preferences are implicitly expressed in the voting distribution among stake holders, through the percentages established by the legislator in the general meeting. By adding this con straint (i.e., the voting distribution) to the DEA model, we enhance the analysis, defining what the legislator considers best practice, and we also make comparisons between management choices and leg islator preferences. Then, the overall efficiency of a SB will be a measure of the agent's ability to take decisions in an economically efficient manner while satisfying regulator preferences. Similarly, ineffi ciency will measure the failure to optimally allocate goals into the transformation process following reg ulator preferences on outputs. Besides, the measure of convergence between the preferences of managers and regulator preferences becomes an indication of the effectiveness of ownership regulation.

This study contributes to the operational research literature by highlighting the potential of applying certain methods developed in this field to analyze new economic problems with clear practical and political implications. In this sense, dual DEA pro grams provide relevant information, the multipliers or weights, which also indicate the relative impor tance (i.e., the order) of outputs. Therefore, as a first contribution, this paper investigates whether it is possible to elucidate if different ownership structures imply different output rankings. Moreover, DEA allows the inclusion of given preferences that are incorporated into performance assessment through restrictions on weights. In a context like the Spanish banking industry, where organizations commercial banks, SBs and credit cooperatives compete on prices or quality of services, with little regulatory restrictions on these variables, the government may influence SBs' economic behavior through the com position of the governing bodies. It allocates control to different stakeholders and defines the vote distri bution among them. Consequently, in this paper, we consider that regulator preferences over outputs are defined by means of the current legislation on SBs' governing bodies a type of weight restriction not previously considered in the DEA literature. More importantly, the comparison of efficiency scores and weights of DEA programs with and with out weight restrictions will allow us to measure the effectiveness of such a regulatory policy. The result of this comparison has important practical implica tions in Spain where there is a hot debate over the future of this organizational form. The discussion focuses on the appropriateness of reducing public participation in the ownership structure of SBs in order to improve their efficiency.

In addition, through these new avenues of appli cation of DEA methods, we are advancing the understanding of the effects that ownership struc ture has on the economic behavior of organizations in four important ways. First, we measure the per formance of organizations with multiple goals, for which profit maximization (or cost minimization) is only one among several goals to be achieved. Sec ond, we examine in detail the ownership structure of organizations, describing differences in the composition of general meetings within the same organizational form. In particular, we empirically investigate the effect that different compositions of general meetings exert on the degree of achievement of corporate goals, and we also test if managers take into account stakeholder preferences at the time of establishing goal priorities. Third, we build an aggregate measure of performance that incorporates the various different regulatory constraints faced by managers in different ownership types, that is, 
different legislator preferences over multiple goals. Finally, we extend the empirical evidence of the effects of public ownership on efficiency, explaining the possible causes of inefficiency.

The remainder of this article is structured as fol lows. In Section 2, we briefly review the key features of savings banks to define their mission and identify the stakeholders. In Section 3, we present the rela tionship between the proposed methodology and the underlying economic problem. The data and variables used in the empirical application are described in Section 4; the results appear in Section 5 , and sensitivity analyses in Section 6. The paper ends with a discussion of the results, limitations and conclusions.

\section{Spanish savings banks: Mission, stakeholders, ownership structures and regulator preferences}

SBs compete among themselves, with commercial banks, and with credit cooperatives. Therefore, they are subject to the general discipline of the loan and deposit markets. This competition is particularly relevant now, after a deregulation process that demands from savings banks similar levels of effi ciency to their private competitors (Kumbhakar et al., 2001). In institutional terms, SBs are private foundations and, as such, their social function requires that part of their profits be allocated to activities that improve the well being of the region where they belong. Moreover, in the absence of shareholders, the ownership of these banks corre sponds to the various different groups represented in the general meeting and, therefore, ownership is not the result of a purchase or exchange as is the case for commercial banks. Even more interesting for our purposes is the presence of multiple goals that the regulator explicitly includes in the savings banks' mission.

\subsection{Mission and stakeholders}

The current situation is mostly the result of Law 31/1985, (known as LORCA), which favored the inclusion of the interests of the regions where sav ings banks are present, along with a more profes sional management of SBs. Thus, on the one hand, savings banks could adapt to the peculiarities of their region, looking for a greater implication of SBs in regional development and, on the other hand, they have experienced an organizational change, trying to balance the interests of the various different social groups. Current regulation estab lishes the composition of the governing bodies (gen eral meeting, board of directors and control commission) of savings banks with representatives from four social groups: $1545 \%$ of the seats for the representatives of depositors, employees take $515 \%$ of the seats, founder entities take $1035 \%$ and, finally, between $15 \%$ and $45 \%$ of the seats are for the public administrations (City Halls, Local and Regional governments).

The result of this particular evolution of the SBs is a group of organizations whose legal nature resem bles that of "commercial non profit organizations" in the words of Hansmann (1996). They undertake the typical activities of banks, searching for eco nomic efficiency and profit maximization but their profits go mostly to social programs and charity.

All these features allow us to talk of multiple goals for SBs; that is, a wide mission justified by the presence of stakeholders represented in the gov erning bodies. ${ }^{1}$ Table 1 summarizes the various dif ferent goals of SBs. As a summary of this, we define the SBs mission in the following terms: "SBs help to make financial services a universal service, rendered under conditions of economic efficiency, preventing abuses of market power, while at the same time con tributing both to a better allocation of the created wealth and to the sustained development of those regions where they are present".

\subsection{Ownership structures and regulator preferences}

In terms of ownership structure, Spanish savings banks can be divided into two groups. The first includes those savings banks controlled by public administrations (henceforth, public SBs); that is, those savings banks in which the public administra tions (PA) hold more than $50 \%$ of the votes in the general meeting of the savings bank. To calculate this, we add local, provincial and regional PAs, along with public founders. The second group is formed by savings banks controlled by insiders (henceforth, insider SBs); that is, savings banks in which employees, depositors and private founders account for $50 \%$ or more of the votes. ${ }^{2}$

\footnotetext{
${ }^{1}$ Although not directly represented in the governing bodies, the regulator also pursues its own goals and, for example, the Bank of Spain plays an active role in monitoring the banks' solvency.

2 Incidentally, this distinction also responds to the European authorities' concern regarding the role of banks controlled by public administrations.
} 
Table 1

Mission and stakeholders for the Spanish savings banks

\begin{tabular}{|c|c|c|}
\hline Mission goals & Description & Stakeholders \\
\hline$y_{1}$ : Universal access to financial services & $\begin{array}{l}\text { Favor popular savings and avoid the exclusion from the } \\
\text { financial system }\end{array}$ & $\begin{array}{l}\text { Founders } \\
\text { Public } \\
\text { Administrations } \\
\text { Employees }\end{array}$ \\
\hline$y_{2}:$ Profit maximization & $\begin{array}{l}\text { Collect savings and make investments under safe and } \\
\text { profitable terms }\end{array}$ & $\begin{array}{l}\text { Depositors } \\
\text { Bank of Spain } \\
\text { Employees }\end{array}$ \\
\hline $\begin{array}{l}y_{3} \text { : Promote competition and prevent monopoly } \\
\text { abuse }\end{array}$ & Combat usury & $\begin{array}{l}\text { Founders } \\
\text { Public } \\
\text { Administrations }\end{array}$ \\
\hline $\begin{array}{l}y_{4}: \text { Make a contribution to social welfare and wealth } \\
\text { distribution }\end{array}$ & Provide services of not-for-profit and charitable nature & Founders \\
\hline$y_{5}:$ Make a contribution to regional development & Take notice of the genuine interests of the territory & $\begin{array}{l}\text { Public } \\
\text { Administrations }\end{array}$ \\
\hline
\end{tabular}

Voting distribution among the stakeholders not only implies differences in ownership structure, it can also reveal the preferences of the regional admin istrations on a bank's goals, which by law have competence to rule on the governing bodies' compo sition. In this matter, legislator preferences are implicitly expressed through the voting distribution among stakeholders in the general meeting.

In public SBs, when the legislator explicitly allo cates more than $50 \%$ of the votes in the general meeting to public administrations, the legislator is showing a preference for the goals attached to this group of stakeholders. As shown in Table 1, the goals of universal access, competition enhancement and regional development should be favored over profit maximization and wealth redistribution.

On the other hand, if the legislator allocates the control of savings banks to insiders, the order of priorities will favor the goals attached to employees, depositors and private founders. That is, the legisla tor is showing a preference for profit maximization and growth over other goals, as depicted in Table 1.

In insider SBs, the group formed by managers and workers enjoy the control, due to the limited ability of depositors the group that typically has the largest percentage of votes to influence the functioning of savings banks. There are at least two reasons that support this fact: (1) depositors' goals are already protected by means of a debt con tract, deposit insurance and an exit option with low costs. (2) The system of electing their representatives (a lottery and a fixed period of time) along with the limited power they hold (one delegate, one vote) make it extremely difficult for this group to act in a coordinated way. In fact, managers exert a remarkable influence on this group. Employees, on the other hand, maintain a stable and lasting rela tion with the organization and, furthermore, they have quite homogeneous preferences. Therefore, it seems reasonable to think that employees share decision power with the managers, as both groups show a clear preference for the entity's growth. Cer tainly, growth implies more reputation and power for managers, along with salary improvements and the possibility of becoming more independent in their decision making. For employees, growth means more opportunities for internal promotion and wage increases. At the same time, both groups also pursue the goal of profit maximization, needed to preserve their jobs and to justify wage increases. According to this view, some rewards to workers (e.g., generous salaries) are simple self entrench ment strategies for incumbent CEOs to avoid their replacement (Pagano and Volpin, 2005).

Last but not least, the legal nature of savings banks makes them more dependent on their ability to grow through the use of internal funds. Given the above, we interpret that the allocation of control to insiders shows legislator preference for growth and profit maximization.

\section{Measuring savings banks' performance with DEA}

Here we describe the methodology used to ana lyze how different ownership structures contribute to the achievement of the goals included in the 
mission of Spanish savings banks. Data Envelop ment Analysis (DEA) techniques turn out to be, in our opinion, particularly relevant in this case for three reasons. First, DEA does not try to estimate the form of the production function, but it uses exist ing observations to elaborate a non parametric empirical frontier where the exact form of the func tion that relates inputs and outputs is unknown. Nevertheless the non parametric, statistical proper ties of DEA estimators are well discussed in several papers (Banker, 1993, 1996). By applying DEA, we obtain an aggregate performance index for each SB in comparison to the rest of observations. This index measures the distance between a particular SB and the frontier. Secondly, by means of a dual transfor mation of the DEA maximization programs, it becomes possible to assign weights to each of the multiple goals. The only assumptions are that each observation should be placed on the extreme frontier or below it, and that the set of weights must be fea sible for any of the sample observations. Finally, these techniques offer the possibility of including a priori information on the relative importance of the variables (Golany, 1988; Thomson et al., 1990; Roll and Golany, 1991; Allen et al., 1997; Halme et al., 1999; Joro et al., 2003). More specifically, if we restrict the weight values associated to the vari ables, we will be able to calculate a new aggregate performance index that takes into account a given preference relation among goals. We now proceed to analyze these three issues formally.

\subsection{Multiplicity of goals and DEA}

We focus on the agency relationship between the different stakeholders and the bank's management team. The contract that regulates this relationship establishes that the principal delegates to the man agers of the bank $i, i=1, \ldots, I$, the task of trans forming the $n$ inputs, $x^{i}=\left(x_{1}^{i}, \ldots, x_{n}^{i}\right) \in \mathfrak{R}_{+}^{n}$, into the goals or outputs that stakeholders are interested in, $y^{i}=\left(y_{1}^{i}, \ldots, y_{5}^{i}\right) \in \mathfrak{R}_{+}^{5}$. If each savings bank uses different quantities of these $n$ inputs to obtain these $m$ outputs, we will construct the set of production possibilities from the data

$$
\begin{aligned}
T= & \left\{(x, y): x \geqslant \sum_{i 1}^{I} \lambda^{i} x^{i} ; y \leqslant \sum_{i 1}^{I} \lambda^{i} y^{i}\right. \\
& \left.\sum_{i=1}^{I} \lambda^{i}=1 ; \lambda^{i} \geqslant 0 ; i=1, \ldots, I\right\},
\end{aligned}
$$

which is the smallest set that includes all observations and satisfies the free input and output disposability conditions. This set also fulfills convexity and the monotonicity assumptions (Banker and Thrall, 1992) and, furthermore, the technology described in (1) exhibits variable returns to scale (VRS). We should mention that Spanish $S B S$ differ widely in size, operational activity, objectives and geographical market. All this leads us to favor a model with VRS.

Once the set of production possibilities $T$ is defined, we formulate the problem of measuring SBs efficiency. We use an output oriented DEA model to analyze the effect that the governance char acteristics of SBs exert on the fulfillment of their mission. The implicit assumption here is that man agement teams aim at maximizing output levels (i.e., the five goals) while keeping the input levels. The optimization problem for a given SB “ $\circ$ ” can be written as the following linear program, solved $I$ times, once for each SB (Banker et al., 1984):

$$
\begin{aligned}
\left(\mathrm{IP}^{\circ *}\right)^{1} & \max \left\{\theta^{\circ} \mid \sum_{i=1}^{I} \lambda_{i}^{\circ} y_{j}^{i} \geqslant \theta^{\circ} y_{j}^{\circ} ; \sum_{i=1}^{I} \lambda_{i}^{\circ} x_{k}^{i} \leqslant x_{k}^{\circ} ;\right. \\
& \left.\sum_{i=1}^{I} \lambda_{i}^{\circ} \quad 1 ; \lambda_{i}^{\circ} \geqslant 0 ; j \quad 1, \ldots, m ; k \quad 1, \ldots, n\right\} .
\end{aligned}
$$

The solution to $(2), \theta^{\circ *} \geqslant 1$, represents the pro portion by which the five outputs or goals of the ana lyzed SB must be increased to move a given bank to the production possibilities frontier (i.e. the frontier of good practices). Therefore, a bank will be efficient only if $\theta^{\circ *}=1$. The inverse of this value is an aggre gate index of performance, $\mathrm{IP}^{\circ *}$, the value of which quantifies, in relative terms, how well managers use the inputs to obtain the maximum level of outputs for stakeholders. Consequently, (1 $\left.\mathrm{IP}^{\circ *}\right)$ measures the degree of inefficiency. Non negative values of $\lambda^{\circ *}$ identify the reference set for the evaluated SB; i.e., the set of banks that define the section of the frontier where that SB is projected. For those cases in which a SB is located on the frontier, we will have $\lambda_{0}^{\circ}=1$ and $\lambda_{i}^{\circ}=0$.

Let us consider now the dual form corresponding to program (2):

$$
\begin{aligned}
\left(\mathrm{IP}^{\circ *}\right)^{1}= & \min \left\{\sum_{k 1}^{n} v_{k}^{\circ} x_{k}^{\circ}+\phi^{\circ} \mid \sum_{j 1}^{m} \mu_{j}^{\circ} y_{j}^{\circ}=1 ; \sum_{k 1}^{n} v_{k}^{\circ} x_{k}^{i}\right. \\
& \left.\sum_{j=1}^{m} \mu_{j}^{\circ} y_{j}^{i}+\phi^{\circ} \geqslant 0 ; v_{k}^{\circ}, \mu_{j}^{\circ} \geqslant 0 ; \phi^{\circ} \text { free } ;=1, \ldots, I\right\} .
\end{aligned}
$$


Program (3) is solved $I$ times as well, and it allows us to simultaneously identify $\phi^{\circ}$, which is a measure of the possible existence of economies of scale, and the optimal output and input weights (or multipliers) for each $\mathrm{SB}$, denoted by $\mu_{j}^{\circ}$ and $v_{k}^{\circ}$ respectively. In doing so, we assume that with the set of weights of the evaluated SB no other entity obtains a value for $\mathrm{IP}^{\circ *}$ over 1 (the point of maximum efficiency corresponding to the frontier). Moreover, the duality theorem guarantees that solutions to programs (2) and (3) become identical.

The weights that solve program (3) represent each SB's achievement of goals (Caporaletti et al., 1999), and there is no other weight combination that, given the possibilities of transformation of this technology, provides a higher performance index (Allen et al., 1997) for the evaluated SB. Therefore, we interpret these weights as a measurement of the relative importance that a given SB confers on its goals. Such weights will be the result of private negotiations between the different stakeholders.

Next, we modify program (3) so that we can incorporate legislator preferences. Thus, we con struct a second performance index to evaluate the managers' performance in terms of the a priori order of priorities. By comparing both indexes we can identify and measure how accurate the managers' interpretation of the legislator prefer ences is.

\subsection{Legislator preferences and DEA}

The inclusion of legislator preferences into pro gram (3) imposes additional restrictions on weights. Provided that these weights represent the relative importance of each goal, legislator preferences are expressed in the form of a given arrangement of the goals included in the mission. Therefore, the additional restrictions to program (3) could be writ ten in terms of marginal rates of transformation (Thomson et al., 1990) or by means of an ordinal relation among the weights (Golany, 1988):

$\mu_{s}^{i} \leqslant \mu_{r}^{i} \leqslant \mu_{t}^{i}$,

where $(r, s, t)$ denote outputs. An interesting advan tage of doing so is that we only need to arrange the weights according to legislator preferences, that is, there is no need to establish the lower or the upper limit. Such a feature is particularly relevant here where the information concerning the composition of the general meeting only allows us to arrange the goals.
According to Section 2, when the legislator allo cates control to the public administrations, prefer ences favor the goals of universal access $\left(y_{1}\right)$, competition enhancement $\left(y_{3}\right)$ and regional develop ment $\left(y_{5}\right)$. Without further additional information to arrange priorities, we can represent such prefer ences in the following way:

$\mu_{1}, \mu_{3}, \mu_{5} \geqslant \mu_{2}, \mu_{4}$.

Similarly, the legislator's preference for those goals associated with insiders, that is, universal ser vice $\left(y_{1}\right)$ and profit maximization $\left(y_{2}\right)$ could be expressed with another set of additional constraints on weights:

$\mu_{1}, \mu_{2} \geqslant \mu_{3}, \mu_{4}, \mu_{5}$.

DEA techniques contemplate the inclusion of restrictions on weights, like Eqs. (5) and (6) into program (3), and as a result we obtain a value, $\mathrm{IPR}_{\mathrm{R}}^{\mathrm{o*}} \in[0,1]$ (where $R$ stands for restricted), which is our second performance index. IPR ${ }^{\circ *}$ indicates the ability to produce, given the transformation pos sibilities of the technology and the preferences of the "social planner", the highest levels of outputs $\left(y_{1}^{i}, \ldots, y_{5}^{i}\right)$ from the fixed endowments of inputs $\left(x_{1}^{i}, \ldots, x_{n}^{i}\right)$. With this new index, we can measure the contribution of a bank's managers to welfare maximization. Thus, ( $\left.1 \mathrm{IPR}^{\circ *}\right)$ indicates the dis tance between the current decisions and the legisla tor's good practice frontier.

Obviously, adding constraints implies a decrease in the performance index, unless the managerial decisions respect the legislator priorities on goals. Therefore, $1 \geqslant \mathrm{IP}^{\circ *} \geqslant \mathrm{IPR}^{\circ *}$. Moreover, by com paring these two indexes we can calculate a third, namely, allocative efficiency (AE):

$\mathrm{AE}=\frac{\mathrm{IPR}^{\circ *}}{\mathrm{IP}^{\circ *}} \leqslant 1$.

This AE index enables us to evaluate how accu rately a manager has implemented the principal's directives at the time of taking decisions. If manag ers do respect legislator priorities, the $\mathrm{IP}^{\circ *}$ perfor mance index, and the one using restrictions on weights, IPR ${ }^{\circ *}$, will be equivalent and allocative inefficiency will not occur, (i.e., $A E=1$ ). In general, one can always decompose the global performance index into the initial performance and the allocative efficiency,

$\mathrm{IPR}^{\circ *}=\mathrm{IP}^{\circ *} \cdot A E$. 
In the following section we show an application of these indexes and measures to the case of Spanish savings banks.

\section{Data and variable description}

The data used in this paper is extracted from the Statistical Yearbook of the Confederation of Sav ings Banks (published by the Spanish Confederation of Savings Banks). We complement this data with three additional sources: the Economic Bulletin of the Bank of Spain, the Green Book of Financial Institutions and individual annual reports. The empirical application covers the period 19982002 , and we construct a pool of all the savings banks contained in the Record of Entities of the Bank of Spain. Thus, the total number of SBs in our sample is of 50, 49, 47, 46 and 46 in the years 1998, 1999, 2000, 2001 and 2002, respectively. ${ }^{3}$ The decision to pool the data is explained by the proportion of the number of annual observations with respect to the number of variables used. Dyson et al. (2001) described a rule of thumb for a DEA model to achieve a reasonable level of discrimination between efficient and inefficient observations. Such condition is not satisfied here for all the annual data and, therefore, we decided to pool the data.

Our sample includes 226 observations (savings bank year). We exclude four observations from the initial sample (238) due to missing data. ${ }^{4}$ Besides, and as a prior step to the estimation of per formance, we analyze the presence of outliers. As is well known, the analysis of efficiency with determin istic DEA models is quite sensitive to the presence of outliers in the sample. This is due to the fact that the frontier could be determined by observations that are extreme points, and this might affect the efficiency evaluation for the rest of entities. In order to overcome these problems, we applied Wilson's (1995) proposal to deal with extreme observations. After this, we exclude eight additional observations from the sample: Municipal de Burgos (all years), Municipal de Vigo (year 1998), Pollensa (year 1999) and Manresa (year 2000).

The next step in modeling SBs efficiency is the specification of inputs and outputs of the produc

\footnotetext{
${ }^{3}$ Three take-over mergers have taken place during this period. In 1999, Vigo SB took over Ourense SB, and in the year 2000, it took over Pontevedra SB. The same year Pamplona SB was taken over by Navarra SB.

${ }^{4}$ These exclusions are the Balearics and Carlet SBs.
}

tion process. A survey of the different conceptual approaches can be found in Berger and Humphrey (1997). Here, we follow the production approach, since it deals with our main objective: to explain how closely a SB moves toward its multiple goals. The analysis focuses on service production and the stakeholders' objectives attained by each SB. More specifically, service production requires the con sumption of physical and material inputs, as well as human resources. Consequently, we select three inputs closely related to these three resources: staff, the use of capital in terms of depreciation, and the use of other inputs.

Furthermore, we select five outputs that repre sent the goals included in the banks' mission. The first goal consists in providing universal access to financial services, that is, the promotion of savings among the popular classes, preventing their exclu sion from the financial system and trying, at the same time, to move these services closer to all citi zens and locations in the territory. We evaluate the contribution of a financial institution to the pre vention of social exclusion (or lack of banking activ ity) through a territorial dimension the proportion of branches in villages and small towns and through the offering of financial services to custom ers with low levels of resources, or small balances. Accordingly, we use two proxies for this goal. The first is the proportion of branches outside the pro vincial capital, which is measured by a Herfindahl type index (Fuentelsaz et al., 2002). ${ }^{5}$ High values of this index mean that SBs locate their branches in small towns. The second is the inverse of the aver age balance of deposits (ABD), calculated as the ratio of the total volume of deposits to the number of current accounts, saving accounts and deposit accounts. Low values of the $\mathrm{ABD}$ ratio imply that the bank is rendering financial services to clients with low incomes (i.e., customers that generate a high cost per unit of deposit).

The second goal is profit maximization, that is, the use of savings to obtain high profits and avoid, at the same time, bankruptcies or insolvencies. Safety improves with the level of reserves, which themselves are an increasing function of the savings

\footnotetext{
${ }^{5}$ These authors measure rivalry among SBs in geographical markets but they do not consider the intra-regional distribution of branches. We think that the ratio of branches outside the capital over the total number of branches captures the idea of proximity to customers more accurately.
} 
Table 2

Average input and output levels

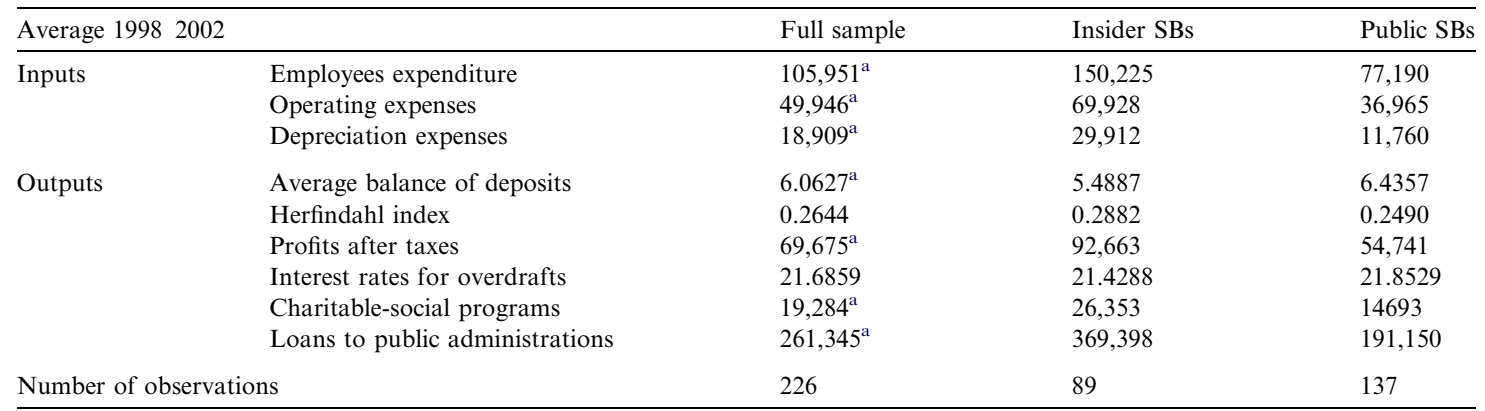

Notes: (a) Average values expressed in thousands of $€$. (b) Average values expressed in thousands of $€$ /account. (c) Average value between 0 and 1. (d) Average value expressed in percentage.

a Significant differences at a 5\% level (ANOVA) within the two control models (insiders and public).

bank's profits. Therefore, we use the variable profit after taxes to measure this second goal.

Competition enhancement and avoidance of monopoly abuse is the third goal included in the mission of savings banks. To obtain better condi tions and lower prices for customers would be the updated version of combating usury, the traditional goal. The contribution of savings banks to competi tion enhancement within the Spanish banking sector should be seen in the use of competitive prices; i.e., prices closer to marginal costs. ${ }^{6}$ Because the public accounts of SBs are not sufficiently detailed, we have not considered the possibility of approaching prices through the average interest rate in the data on Assets and Liabilities. Nevertheless, the Bank of Spain publishes the (non regulated) interest rates applied by financial institutions to their clients: prime rates, interest rates on overdrafts in checking accounts and interest rates for exceeding the limit. To measure the difference between price and mar ginal cost in this case, we use the interest rate for overdrafts as an indicator of price. We rely on the fact that the people that pay such a price are pre cisely those with less bargaining power (as opposed to what happens with the prime interest rate) and, consequently, the SB has leeway to exercise its

\footnotetext{
${ }^{6}$ When firms compete in a non-differentiated market á la Cournot, profit maximization requires satisfying the condition: $\left(p_{i} c_{i},\right)\left(p_{i}\right)^{1}=S_{i}\left|e_{p}\right|^{1}$; where $p_{i}, c_{i}, S_{i}, e_{p}$ denote price, marginal cost, market share, and price-elasticity for the firm $i$, respectively. Solving for market share and dividing by the firm $j^{\prime} s$ market share, it follows that the ratio of market shares should be equal to the ratio of margins.
}

monopoly power on them. On the other hand, we use the Spanish Confederation of Savings Banks reference on interest rates for assets published on December 31 of each year as an approach to mar ginal cost. Since the difference between price and marginal cost becomes a measure of market power, we use the inverse of that difference in our empirical application as a proxy of the SBs' contribution to "competition enhancement". Thus, the indicator is the inverse of the difference between the interest rate for overdrafts and the reference interest for assets.

The fourth goal is the contribution to wealth dis tribution and welfare, measured by the amount of resources that SBs spend on "obra social", that is, services with a charitable or social character.

Finally, the contribution to regional development could be understood as the provision of funds that generate social externalities that the private sector does not provide. This lack of interest on the part of the private sector could be compensated by the regional administrations. Thus, we calculate the proportion of loans (in euros) granted to the Public Administrations over the total volume of loans.

Table 2 presents some descriptive statistics. One important methodological issue in this approach is the use of multiple variables expressed in different units, percentages or indexes. This fact increases the difficulties of estimating performance indexes. Moreover, the measuring approach will also affect the calculation of weights and restrictions that rep resent legislator preferences. Following the recom mendations found in Dyson et al. (2001), we first express all variables in percentages and, later on, we standardize each variable. 


\section{Empirical results}

\subsection{Aggregate performance indexes under a common} frontier

Table 3 contains the summary statistics for the aggregate performance indexes calculated using the pooled frontier. In order to evaluate the man agement of SBs, the performance index that incor porates the preferences revealed by the legislator (IPR) provides us with a measurement of the over all efficiency attained by the bank. The IPR reflects differences both in goal achievement (performance index, IP) and optimalization of goal mix (alloca tive efficiency, $A E$ ). According to the figures in Table 3, insider SBs exhibited higher performance indexes than public SBs in every efficiency measure. The differences observed in performance indexes for the insider SBs and the public SBs are all statisti cally significant, suggesting that insider SBs oper ated closer to the pooled frontier than public SBs did.

In particular, the average IPR for the insider banks is $82.76 \%$ and $75.45 \%$ for public SBs. These results indicate that those banks controlled by insid ers could increase their outputs or the level of their mission's goals by $17.24 \%$, on average, while keep ing their current consumption of inputs constant. This figure expresses the level of overall inefficiency of insider SBs. For those SBs controlled by public administrations, inefficiency increases to $24.55 \%$. In order to better explain the reasons for these num bers, we break down the IPR index into two: the performance index without restrictions (IP) and the allocative efficiency (AE). As shown in Table 3 , a larger proportion of the overall inefficiency in the SBs seems to obey poor IP ratios and, to a lesser extent, problems related to allocative efficiency. We observe that insider SBs are more efficient than pub lic SBs when we maximize the mission without imposing restrictions on weights. More specifically, insider SBs reach an IP of $84.04 \%$, while the aggre gate performance index drops to $79.94 \%$ in the case of public SBs. Concerning AE, efficiency reaches $98.53 \%$ when insiders have control, in contrast to $94.38 \%$ for public SBs.

Two main conclusions follow. First, managers respect the priority order defined by the legislator in both types of SBs; the AE index attains values close to $100 \%$ in both groups. Accordingly, the overall inefficiency (IPR) of savings banks can be explained, mainly, in terms of technical inefficiency (IP). Second, according to the IP figures insider SBs perform better than public SBs. This better per formance of the insider SBs is mainly due to their managers' ability to use productive resources and improve their stakeholders' goals more efficiently than public SB managers.

Table 3

Aggregate performance indexes: common frontier

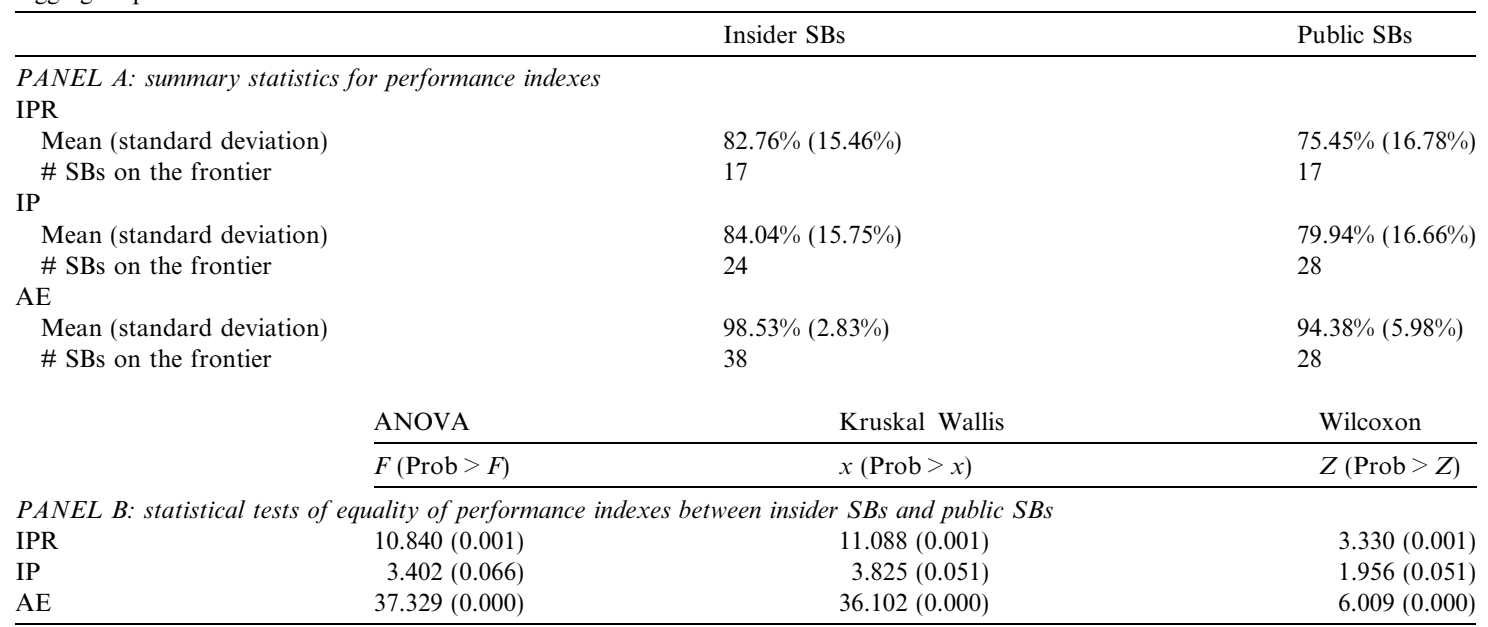

Notes: IPR: performance index with preferences revealed by the legislator. IP: performance index as the result of private negotiations among stakeholders. AE: allocative efficiency. The null hypotheses are that the average of the sample (ANOVA), the functions of distribution (Kruskal Wallis) and the median (Wilcoxon) of the performance indexes for the insider SBs and public SBs are equal. 


\subsection{Aggregate performance indexes under differentiated frontiers}

The presence of different ownership forms raises an important issue: we must decide whether to com pute efficiency by means of a single frontier that includes all savings banks or, alternatively, a differ ent frontier for each bank type. The above results, based on the use of a common frontier, would turn out to be inaccurate if the hypothesis of identical frontiers failed to be sustained. As Altunbas et al. (2001) have already pointed out, two frontiers will be more appropriate if each ownership type pursues different objectives, since in doing so technology dif ferences will be controlled for. Moreover, Mester (1993), who estimated a separate (cost) frontier for each ownership type, argued that results obtained under a common frontier confound technology choice and inefficiency. Nevertheless, researchers have rarely recognized the effect of technology choice on efficiency, and few scholars (Cebenoyan et al., 1993; Elyasiani and Mehdian, 1992) have tested the underlying technologies in their samples. When no significant differences are found, the use of a common frontier seems adequate; otherwise comparing efficiency values obtained from a single frontier becomes inappropriate. To test the hypoth esis of identical frontiers (technologies) for insider and public SBs, we apply a two stage test already used in the DEA literature (Elyasiani and Mehdian, 1992). In a first stage, performance indexes are eval uated for the joint sample, assuming they share a common technology. In the second stage, these indexes are calculated for each subsample, assuming the presence of different technologies. Under the null hypothesis, the ordering of SBs on the basis of their performance indexes for the joint sample turns out to be the same as that of calculating per formance indexes separately for each subsample. Then, if the null hypothesis cannot be accepted, as is the case, we must evaluate the managers after controlling for technology.

Table 4 shows the results of the test and suggests that the average of the sample (ANOVA), the distri bution functions (Kruskal Wallis) and the median (Wilcoxon) of the performance indexes in the com bined sample and the separate samples are statisti cally different, at a 5\% significance level. Therefore, we must assume the use of different tech nologies for each type. Furthermore, this result is independent of the performance index chosen for the test.
Table 4

Statistical test of equal technologies between insider and public savings banks

\begin{tabular}{lllr}
\hline & ANOVA & Kruskal Wallis & \multicolumn{1}{l}{ Wilcoxon } \\
\cline { 2 - 4 } & $F(\operatorname{Prob}>F)$ & $x(\operatorname{Prob}>x)$ & \multicolumn{1}{c}{$Z(\operatorname{Prob}>Z)$} \\
\hline IPR & $23.620(0.000)$ & $25.395(0.000)$ & $12.131(0.000)$ \\
IP & $13.502(0.000)$ & $12.663(0.000)$ & $11.177(0.000)$ \\
AE & $34.404(0.000)$ & $31.693(0.001)$ & $8.678(0.000)$ \\
\hline
\end{tabular}

Notes: IPR: performance index with preferences revealed by the legislator. IP: performance index without restrictions. AE: allocative efficiency. The null hypotheses are that the average of the sample (ANOVA), the functions of distribution (Kruskal Wallis) and the median (Wilcoxon) of the performance indexes for the pooled frontier and the group-specific frontiers are equal.

Following Elyasiani and Mehdian (1992), we can also justify this technological difference between the two groups of SBs by the idiosyncratic characteris tics of each organizational model, either in terms of its productive specialization or its organizational characteristics. Regarding product specialization, the descriptive statistics shown in Table 2 indicate that public SBs are smaller in size. This could explain why these entities are more present in less competitive regional markets (where they can offer services at higher rates of interest). On the other hand, insider SBs are much larger in size and, pre dictably, they participate in more competitive mar kets where they must also face commercial banks as competitors. Savings banks of such relevance as "Caixa d'Estalvis i Pensions de Barcelona" or "Caja Madrid" (ranked as No. 56 and No. 98, respec tively, in the The Banker 2003 Top 1000 World Bank ranking) belong to this group. Both their size and the intensity of competition in the markets in which they operate certainly demand more sophisti cated management and, consequently, more quali fied managers as well. Moreover, these firms achieve higher levels of efficiency.

Regarding organizational characteristics, we can also say that ownership structure seems to have an effect on SB efficiency. More specifically, those SBs with an ownership structure that allocates a major ity of control rights to PA have lower performance indexes. This indicates that a significant presence of PA inside the governing bodies excessively politi cizes the firm, hindering decision making and exert ing, eventually, a negative effect on efficiency.

For the rest of the paper, we evaluate the man agement practices of $S B S$ after controlling for tech nology. The common frontier results could still be of certain interest, even when the null hypothesis 
Table 5

Aggregate performance indexes: Group-specific frontiers

\begin{tabular}{|c|c|c|c|}
\hline & \multicolumn{2}{|r|}{ Insider SBs } & Public SBs \\
\hline \multicolumn{4}{|c|}{ PANEL A: summary statistics for performance indexes } \\
\hline \multicolumn{4}{|c|}{ IPR } \\
\hline \multicolumn{2}{|l|}{ \# SBs on the frontier } & 29 & 45 \\
\hline \multicolumn{4}{|l|}{ IP } \\
\hline \multicolumn{2}{|l|}{ Mean (standard deviation) } & $90.32 \%(11.60 \%)$ & $85.09 \%(15.39 \%)$ \\
\hline \multirow{4}{*}{$\begin{array}{l}\text { Mean (standard deviation) } \\
\text { \# SBs on the frontier }\end{array}$} & & $99.53 \%(0.92 \%)$ & $98.09 \%(3.06 \%)$ \\
\hline & & 59 & 72 \\
\hline & ANOVA & Kruskal Wallis & Wilcoxon \\
\hline & $F($ Prob $>F)$ & $x($ Prob $>x)$ & $Z($ Prob $>Z)$ \\
\hline
\end{tabular}

Notes: IPR: performance index with preferences revealed by the legislator. IP: performance index as the result of private negotiations among stakeholders. AE: allocative efficiency. The null hypotheses are that the average of the sample (ANOVA), the functions of distribution (Kruskal Wallis) and the median (Wilcoxon) of the performance indexes for the insider SBs and public SBs are equal.

of identical technologies has been rejected. In partic ular, the findings under a pooled frontier will rein force and strengthen the results obtained from the group specific frontier if both evaluations are con sistent (Elyasiani and Mehdian, 1992, 1995). That being said, the reported efficiency values can differ substantially between both estimation procedures (as it can be seen by comparing Tables 3 and 5) because group specific frontiers envelope the data more closely.

In order to evaluate the management of SBs, the performance index that incorporates the preferences revealed by the legislator, IPR, measures the overall efficiency attained by the bank. Due to the construc tion of this model, all SBs now fulfill the externally imposed restrictions. Thus, we evaluate manage ment in an agency framework that specifies the goals to be reached and the order of preference among them. The results in Table 5 indicate that IPR is higher, on average, for the subsample of insi der SBs, showing that they are, on average, more efficient in relation to their own frontier than public SBs. The insider subsample frontier is formed by those entities that, after "exhausting" the transfor mation possibilities their own technology offers, still respect the order of priorities defined ex ante by the legislator. A total of $29 \mathrm{SBs}$ form this frontier, almost $32.58 \%$ of the subsample. Furthermore, the distance between the remaining SBs and this fron tier, that is, total inefficiency, can be quantified in $10.10 \%$. The performance index of public SBs is lower, $85.53 \%$. In other words, their average ineffi ciency amounts to $14.47 \%{ }^{7}$

Table 5 also shows the results of the analysis on how well the SBs maximize their mission when leg islator preferences are not taken into account, the above mentioned performance index (IP). As these results show, when we maximize the mission with out imposing restrictions on weights; i.e., when we apply programs (2) or (3) to each subsample, we observe that 31 entities lie on the frontier, or $34.83 \%$ of the group, reaching an IP of $90.32 \%$. This value indicates that, with the current consumption of inputs, the outputs represent $90 \%$ of the transfor mation possibilities that the technology offers. Therefore, to reach the frontier, insider SBs should increase all their outputs by $10 \%$ on average, a fig ure that represents average inefficiency.

In the case of public SBs, 39 entities lie on the frontier and the aggregate performance index drops to $85.09 \%$. From these results, we can state that the management of insider SBs attains results which are closer to their group's frontier of good practice. In

\footnotetext{
${ }^{7}$ We have assumed a VRS DEA model. We have also tested the case of constant returns to scale and the efficiency levels for all SBs remain practically the same: $94.5 \%$ for public SBs and $97.4 \%$ in the case of insider SBs.
} 
other words, they are more efficient than public SBs, if we define efficiency as the managers' ability to reach their goals with the productive resources given and the preferences on goals determined by negoti ation among the stakeholders.

Furthermore, we also evaluate the managers on two lines: their skill in transforming inputs into stakeholders' goals and their ability to implement legislator preferences. For this, we have calculated the allocative efficiency (AE), as described in Eq. (7). From the results shown in Table 5, one can see that AE reaches values close to $100 \%$ in both groups. In particular, when insiders have control, $\mathrm{AE}$ is 99.53 and rises to $98.09 \%$ when SBs are con trolled by a PA. It is interesting to highlight that, despite the moderate decrease in the number of SBs placed on the respective frontiers, the number of allocative efficient SBs increases considerably $(66.29 \%$ for insiders and $52.55 \%$ for PA), once we include legislator preferences.

Managers seem to identify quite accurately the legislator's preferences as revealed in the composi tion of governing bodies. Similarly, if we assume that managerial decisions are the result of negotia tion between various different groups, and final decisions are taken according to given corporate governance rules and stakeholders' power, our results indicate that there is no difference between the formal allocation of control (through voting dis tribution) and the real control eventually exercised by each group. So, in practice, from the negotiation process between stakeholders one obtains an order of preferences not so different from the preferences defined ex ante by the legislator. Consequently, the differences in performance between both types of savings banks will be better explained by the managers' ability to use their productive resources in a more efficient way and reach the goals pursued by the stakeholders. In other words, the difference observed in the IPR index does not respond so much to a problem of interpretation of the legisla tor's preferences (allocative efficiency), as to a prob lem in goals implementation (performance index without restrictions, IP). Furthermore, these results

Table 6

Goals relative weights: Group-specific frontiers

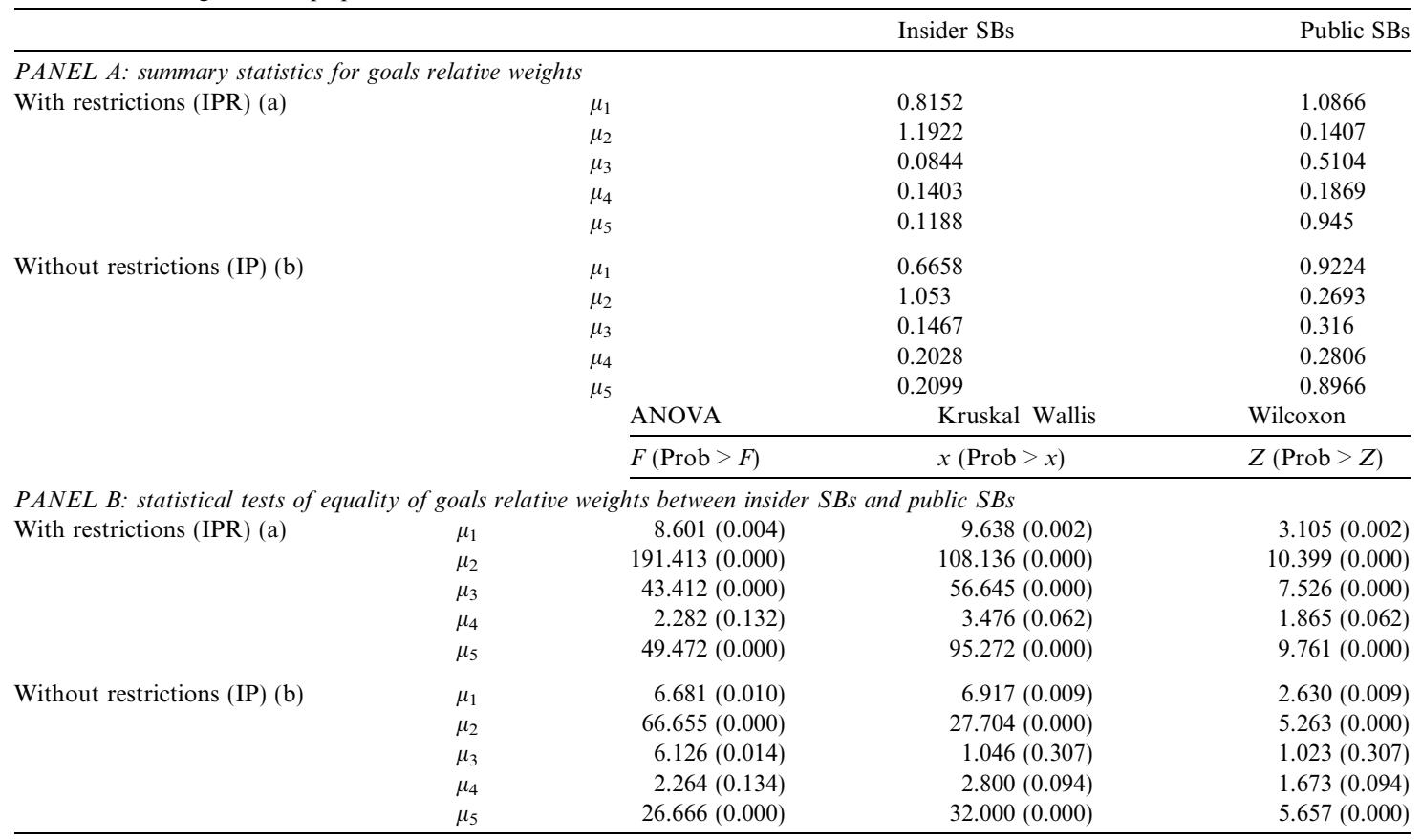

Notes: (a) Weights are obtained by applying the program (3) first to public SBs, and then adding restrictions (5). Similarly for insider SBs, adding restrictions (6) to program (3). (b) Weights are obtained by applying the program (3) to each SBs subsample.

The null hypotheses are that the average of the sample (ANOVA), the functions of distribution (Kruskal Wallis) and the median (Wilcoxon) of the goal weights are equal for insider SBs and public SBs. 
are independent of the frontier, and after control ling for technology we can now attribute the lack of efficiency in a particular type of SB to its managers.

\subsection{Priorities and control types}

After verifying that allocative inefficiency turns out to be very low, we focus on the identification of the mission's structure. That is, we want to deter mine the relative importance of each goal as the result of private negotiation among stakeholders. Later, we compare this with the preference order defined ex ante by the legislator.

The weights attached to each goal are obtained from the application of the dual program (3) to the two subsamples. According to the results shown in Table 6 , the goals that receive more attention in insider controlled SBs are profit maximization $\left(\mu_{2}\right)$ and universal financial service $\left(\mu_{1}\right)$, while enhancing competition $\left(\mu_{3}\right)$ and regional development $\left(\mu_{5}\right)$ are poorly valued. These results corroborate the initial intuition that the allocation of control rights to insiders has consequences on the choice of goals finally implemented, confirmed by their emphasis on growth and the search for higher levels of profits.

As far as public SBs are concerned, universal financial service $\left(\mu_{1}\right)$ and regional development $\left(\mu_{5}\right)$ are the goals that receive larger weights. Com petition enhancement $\left(\mu_{3}\right)$ is the goal placed in third position, although the pairwise comparisons between this weight and those attached to profit maximization $\left(\mu_{2}\right)$ and contribution to social wel fare $\left(\mu_{4}\right)$ are statistically insignificant (Wilcoxon test). It is also worth emphasizing that the last goal forpublic SBs, in terms of relative importance, is profit maximization $\left(\mu_{2}\right)$.

Although not reported here, we have also run this analysis with differences in bank size and the main results remain unchanged. Nevertheless, as size increases, the economic goal gains in impor tance inside the objective function of insider SBs. In fact, it becomes the only goal for SBs in the fourth quartile (i.e., for very large banks, economic performance receives a much larger weight com pared to other goals).

Due to the characteristics of the optimization program, both groups of savings banks respect the priority relation entrusted to them by the legislator (defined in Eqs. (5) and (6)). Nevertheless, the infor mation obtained by comparing weights before and after the use of constraints is far from irrelevant and it suggests possible ways for improving the IPR performance of savings banks as we mention later in the section of conclusions.

\section{Sensitivity analyses}

We conducted three additional analyses to check the robustness of the above results. These results confirm the main conclusions of the paper. Now, we briefly summarize the motivation for and the main findings of these analyses. ${ }^{8}$

We first checked the influence of weight multi plicity. As is widely known, DEA constructs a piece wise linear surface, implying that, for each efficient firm (i.e., an observation that defines a vertex of the enveloping frontier there is not just one but a multiple number of weights that could be used (see Rosen et al., 1998). Note, however, that the problem of weight multiplicity is not applicable to inefficient observations: the optimal weights for inefficient observations are unique and these weights are deter mined by the slope of the frontier where they are projected). Therefore, if the average results pre sented in Table 6 , for weights without restrictions, were calculated for inefficient firms only, goal prior ities would be exactly the same for the two types of SBs.

Additionally, in an attempt to assess whether our results are sensitive to other sets of optimal weights, we used optimization programs aimed at computing upper and lower bounds for output weights. More specifically, we used a procedure defined by Banker and Thrall (1992, pp. 81 82). This procedure con sists of replacing the objective function of the pro gram (3) by $\operatorname{Max} \mu_{j}^{\circ}$ (to compute maximum weights) or $\operatorname{Min} \mu_{j}^{\circ}$ (to compute the minimum) and adding the constraint $\sum_{k} v_{k}^{\circ} x_{k}^{\circ}+\phi^{\circ}=\mathrm{IP}^{\circ *}$ to the constraints included in (3). After applying these pro grams, we found that the weights shown in Table 6 belong to the interval of possible values for each weight interval defined by the maximum and mini mum weights. Additionally, this new application showed that the relative importance of each goal, identified through upper and lower bounds on mul tipliers, was consistent with the results discussed in Section 5.3. Specifically, the results showed that insider SBs give priority to the goals of profit max imization $\left(\mu_{2}\right)$ and universal financial service $\left(\mu_{1}\right)$.

\footnotetext{
${ }^{8}$ These tests were pointed out by two anonymous referees. Full results are available upon request.
} 
Concerning the public SBs, universal financial ser vice $\left(\mu_{1}\right)$, regional development $\left(\mu_{5}\right)$ and competition enhancement $\left(\mu_{3}\right)$ receive larger weights.

Second, we analyzed the relationship between input/output measures and weights. One concern, already pointed out by Sarrico and Dyson (2004) and Dyson et al. (2001), is the dependence of abso lute weights (those obtained from applying program (3)) on the units of measurement of the input/output data set. Their recommendation is to compute vir tual input/outputs, that is, the product of the input (output) level and the optimal weight for that input (output). Proceeding in this way, virtual variables become dimensionless and the results are easier to interpret. We followed their recommendation and the results were again highly consistent with those ones reported in Section 5. The results from the model without restrictions indicate that the goals that receive more attention in insider SBs are profit maximization $\left(\mu_{2} \times y_{2}=0.41\right)$ and universal finan cial service $\left(\mu_{1} \times y_{1}=0.34\right)$; while enhancing com petition $\left(\mu_{3} \times y_{3}=0.06\right)$, contribution to social welfare $\left(\mu_{4} \times y_{4}=0.09\right)$ and regional development $\left(\mu_{5} \times y_{5}=0.09\right)$ obtain low values. Similarly, uni versal financial service $\left(\mu_{1} \times y_{1}=0.37\right)$ and regional development $\left(\mu_{5} \times y_{5}=0.26\right)$ become the goals that receive larger weights in public SBs. Only the com petition enhancement goal $\left(\mu_{3} \times y_{3}=0.10\right)$, for public SBs, is ranked lower in terms of virtual goals (profit maximization, $\mu_{2} \times y_{2}=0.14$, and contribu tion to social welfare, $\mu_{4} \times y_{4}=0.13$ ), but these dif ferences are statistically insignificant (Wilcoxon test). This is not such a surprising result if we note the small distance (also statistically insignificant, Wilcoxon test) between its absolute weight value $\left(\mu_{3}=0.32\right)$ and the weights for profit maximization $\left(\mu_{2}=0.27\right)$ and contribution to social welfare $\left(\mu_{4}=0.28\right)$.

Finally, we studied in further detail the time evo lution of the results when performing two kinds of analyses. The fist analysis consists of measuring the productivity change over time by means of Malmquist indexes. As discussed in Camanho and Dyson (2006), this index performs comparisons rel ative to year specific frontiers only, without pooling the observations to form a common frontier for all years. In turn, this index can be broken down into two components: one measuring the catching up effect (efficiency change) and the other one captur ing the shift in the production frontier (technical change). The latter value is critical because only when the annual frontiers share the same technol ogy can the yearly data be pooled and, therefore, may the efficiency scores be estimated relative to a pooled frontier. The results show modest changes in productivity during the period 1998 2002. The technical change values are close to one in both sub samples (insider and public SBs). This indicates that the best practice frontier has remained immo bile, suggesting that the use of a pooled frontier with all years is a plausible solution and, further more, its use in our application has not biased the results. Starting from this evidence, we also calcu lated the descriptive statistics for efficiency scores and weights of each year in our sample, making use of the group specific frontiers with pooled data. The results of these analyses reveal several facts. First, the goal priorities are stable for each sub sam ple across years and are also consistent with the results shown in Table 6. Second, the frontiers show low stability, particularly in the insider SBs sub sample: 14 different firms (out of 22) have belonged in at least one year to the efficient set (18 of 30, in the public SBs sub sample). Comparing both sub samples, regularity is higher in the public group, as five savings banks define the frontier in all years. Third, untabulated results for the evolution of effi ciency show a decreasing trend in efficiency scores. This result is independent of the indicator of perfor mance employed (IPR or IP) and the sub sample analyzed (public or insider SBs). We conjecture that this result can be explained by the increasing pressure placed on SBs to operate like commer cial banks pressure that leads SBs to focus more on the efficiency of their brokerage activities, pro gressively avoiding some activities that revert back to society (and penalizing their $I P R$ and IP scores).

\section{Conclusions}

In this paper, we have investigated the connec tions between regulation, ownership structure and the economic behavior of organizations. We have also argued that the Spanish savings bank (SBs) industry may be an interesting case study for clarify ing these relationships. There are several distinctive features that make these banks interesting. Firstly, they pursue a wide mission that explicitly mentions several goals. Secondly, SBs are unlisted and have an ownership structure where different stakeholders take part. In this sense, current European legislation distinguishes between savings banks controlled by public administrations and savings banks controlled 
by insiders. And thirdly, the legislator occasionally interferes in the SBs' decision taking, trying to impose their own preferences through specific regu lation on the composition of governing bodies. Clearly, some of these features are also present in other organizational forms such as publicly owned firms, mutual firms and other non profit organi zations.

Taking these elements into account, we have made use of several data envelopment analysis (DEA) models to assess in the first instance the effect of ownership differences on the SBs' ability to transform inputs into corporate goals. Then, we have examined whether the legislator has succeeded in imposing its preferences inside the organization. By applying DEA to our data, we have built up three performance indexes: technical efficiency, overall efficiency and allocative efficiency indexes. Using these indexes, SBs managers have been eval uated on the basis of their ability to conform to leg islator priorities (i.e. allocative efficiency), and their efficient use of resources to reach the firm's goals (i.e. technical efficiency). Additionally, we have used DEA to obtain the weights attached to the goals. These weights must be interpreted as the relative importance assigned to each goal and, as such, they are the outcome of negotiations among stakeholders after taking into account some previously defined governance rules and the specific allocation of con trol rights. Weight comparisons also become possi ble in our analysis because each variable has been previously standardized.

Our results show that the differences in the over all efficiency of banks are not so much explained by managers' mistakes in interpreting the current legis lation (allocative inefficiency is practically nonexis tent), as by the presence of substantial differences in the managers' skills in transforming inputs into goals for stakeholders (technical efficiency). These results suggest that banks' prioritization of goals seems to be coherent, in principle, with legislator preferences. More specifically, we have verified how the voting distribution (established by the leg islator) in savings banks' general meetings has an effect on the goals to be reached and, furthermore, follows the direction pursued by the legislator. Thus, the goals of regional development and univer sal financial services receive more attention when public administrations hold a majority of seats on the governing bodies, whereas the attainment of economic growth and higher profits are the favored goals when insiders hold control.
The main conclusion to be reached from this research is that differences in the ownership structure give rise to differences in SBs technology and their priorities, including the importance attached to profit maximization. This is why we hold that sav ings banks, in particular, and other multi objective organizations in general, should not be evaluated exclusively in terms of profits (or costs), since they pursue multiple and different goals which, presum ably, they would not carry out if their ownership structure or their goal priorities were different. Fol lowing this argument, it does not seem reasonable to evaluate managers in these organizations by their economic results alone, especially when the legislator (for example, by regulating the composition of gov erning bodies) affects the technological possibilities of the savings bank and encourages managers to pursue different goals, which might even be in con tradiction with profit maximization.

Moreover, in our empirical application, we have found that, by reducing the relative weight of the public administrations in decision bodies (a decision similar to that of partially privatizing a state owned enterprise), the legislator is changing the structure of priorities (i.e., it increases the weight of the "profit maximization" goal to the detriment of other goals such as "regional development") while causing only a slight increase in the overall perfor mance index (in our analysis, IPR). Global ineffi ciency remains, nevertheless, high in our study (around 10\%). Hence, to the extent that the differ ences we found among the ownership structures in the SBs sector are due to differences in technical effi ciency, any further reform should pay particular attention to the effects that new regulation may have on enhancing the technical ability to transform inputs into outputs, rather than in changing the mis sion to favor more financial oriented goals.

Our study can be extended in different ways. First, it may be of interest to pursue a more finely grained analysis of regulator preferences. In this application, and in accordance with European regulations, we distinguished two types of banks: those where the legislator has allocated control (more than $50 \%$ of the votes) to public administrations and those where this threshold of $50 \%$ in not surpassed. From this dis tribution of control rights we inferred the regulator's preferences over the goals; preferences that were sub sequently incorporated into DEA assessments through ordinal relations among weights. Therefore, an attractive possibility for further refining the anal ysis of the impact of regulation on efficiency would 
be to consider the percentage of votes assigned to each stakeholder. In this new scenario, it would be possible to rewrite the constraints included into DEA models. Moreover, proceeding in this way, it would be also possible to define firm year specific weight restrictions, as a function of the vote distribu tion among stakeholders in its general meeting for each year. As constraints become more severe, the efficiency scores of assurance region models will decrease, increasing allocative inefficiency.

Finally, future work should attempt to expand the sample to include other organizational forms such as commercial banks and credit cooperatives that compete in the Spanish banking industry. Inter estingly, these other types of banks also present sub stantial differences in terms of regulation, ownership structure and corporate goals. Thus, this richer data set would allow us to examine in greater depth the possible connections between regulation, ownership structure and economic behavior. These issues will be the subject of future research.

\section{Acknowledgements}

The authors would like to express their gratitude to Dr. Robert Dyson and two anonymous referees for many constructive comments and hints which helped improve the paper. We also acknowledge the financial support of the Spanish Ministry of Education and Science (grants \# SEJ2004 07530 CO4 02/ECON and SEJ2006 01731). The usual dis claimers apply.

\section{References}

Allen, R., Athanassopoulos, A., Dyson, R.G., Thanassoulis, E., 1997. Weights restrictions and value judgments in data envelopment analysis: Evolution, development and future directions. Annals of Operations Research 73 (0), 1334.

Altunbas, Y., Evans, L., Molyneux, P., 2001. Bank ownership and efficiency. Journal of Money, Credit and Banking 33 (4), 926954.

Banker, R.D., 1993. Maximum likelihood, consistency and data envelopment analysis: A statistical foundation. Management Science 39 (10), 12651273.

Banker, R.D., 1996. Hypothesis tests using data envelopment analysis. The Journal of Productivity Analysis 7, 139159.

Banker, R.D., Charnes, A., Cooper, W.W., 1984. Some models for estimating technical and scale inefficiencies in data envelopment analysis. Management Science 30 (9), 10781092.

Banker, R.D., Thrall, R.M., 1992. Estimation of returns to scale using data envelopment analysis. European Journal of Operational Research 62 (1), 7484.

Berger, A.N., Humphrey, D.B., 1997. Efficiency of financial institutions: International survey and directions for future research. European Journal of Operational Research 98 (2), 175212.

Bhattacharya, A., Lovell, C.A.K., Sahay, P., 1997. The impact of liberalization on the productive efficiency of Indian commercial banks. European Journal of Operational Research 98 (2), 332345.

Camanho, A.S., Dyson, R.G., 2006. Data envelopment analysis and Malmquist indices for measuring group performance. Journal of Productivity Analysis 26, 3549.

Caporaletti, L.E., Dulá, J.H., Womer, N.K., 1999. Performance evaluation based on multiple attributes with nonparametric frontiers. Omega 27 (6), 637645.

Cebenoyan, A.S., Cooperman, E.S., Register, C.A., Hudgins, S.C., 1993. The relative efficiency of stock versus mutual S\&L: A stochastic cost frontier approach. Journal of Financial Services Research 7 (2), 151170.

Chang, C.E., Hasan, I., Hunter, W.C., 1998. Efficiency of multinational banks: An empirical investigation. Applied Financial Economics 8, 689696.

Dyson, R.G., Allen, R., Camanho, A.S., Podinovski, V.V., Sarrico, C.S., Shale, E.A., 2001. Pitfalls and protocols in DEA. European Journal of Operational Research 132 (2), 245259.

Elyasiani, E., Mehdian, S.M., 1992. Productive efficiency performance of minority and nonminority-owned banks: A nonparametric approach. Journal of Banking \& Finance 16 (5), 933948.

Elyasiani, E., Mehdian, S.M., 1995. The comparative efficiency performance of small and large US commercial banks in the pre- and post-deregulation eras. Applied Economics 27, 1069 1079.

Fried, H.O., Lovell, C.A.K., Vanden Eekaut, P., 1993. Evaluating the performance of US credit unions. Journal of Banking \& Finance 17 (2 3), 251265.

Fuentelsaz, L., Gómez, J., Polo, Y., 2002. Evidence from the Spanish banking sector after deregulation. Strategic Management Journal 23 (3), 245264.

Fukuyama, H., Guerra, R., Weber, W.L., 1999. Efficiency and ownership: Evidence from Japanese credit cooperatives. Journal of Economics and Business 51 (6), 473487.

Golany, B., 1988. A note on including ordinal relations among multipliers in DEA. Management Science 34 (8), 10291033.

Grifell-Tatjé, E., Lovell, C.A.K., 1997. The sources of productivity change in Spanish banking. European Journal of Operational Research 98 (2), 364380.

Halme, M., Joro, T., Korhonen, P., Salo, S., Wallenius, J., 1999. A value efficiency approach to incorporating preference information in data envelopment analysis. Management Science 45 (1), 103115.

Hansmann, H., 1996. The ownership of enterprise. Harvard University Press, London.

Joro, T., Korhonen, P., Zionts, S., 2003. An alternative approach to improve estimates of value efficiency in data envelopment analysis. European Journal of Operational Research 149 (3), 688699.

Kumbhakar, S.C., Lozano-Vivas, A., Lovell, C.A.K., Hasan, I., 2001. The effects of deregulation on the performance of financial institutions: The case of Spanish savings banks. Journal of Money, Credit and Banking 33 (1), 101120.

Lins, M.P.E., Sollero, M.K.V., Calôba, G.M., Moreira da Silva, A.C., 2007. Integrating the regulatory and utility firm perspectives, when measuring the efficiency of electricity 
distribution. European Journal of Operational Research 181 (3), 14131424.

Lozano Vivas, A., 1997. Profit efficiency for Spanish savings banks. European Journal of Operational Research 97 (2), 381394.

Lozano Vivas, A., 1998. Efficiency and technical change for Spanish banks. Applied Financial Economics 8 (3), 289300.

Maudos, J., Pastor, J.M., Pérez, F., 2002. Competition and efficiency in the Spanish banking sector: The importance of specialization. Applied Financial Economics 12 (7), 505516.

Maudos, J., Pastor, J.M., 2003. Cost and profit efficiency in the Spanish banking sector (1985 1996) a non parametric approach. Applied Financial Economics 13 (1), 112.

Mester, L.J., 1993. Efficiency in the savings and loan industry. Journal of Banking \& Finance 17 (2 3), 267286.

Pagano, M., Volpin, P., 2005. Managers, workers, and corporate control. The Journal of Finance 60, 841868.

Pastor, J.M., 1995. Eficiencia, cambio productivo y cambio técnico en los bancos y cajas de ahorro espanolas: Un análisis de la frontera no paramétrico. Revista Espanola de Economía 12,3573 .

Piesse, J., Townsend, R., 1995. The measurement of productive efficiency in UK building societies. Applied Financial Eco nomics 5 (6), 397407.

Roll, Y., Golany, B., 1991. Alternative methods of treating factor weights in DEA. Omega 21 (1), 99109.

Rosen, D., Schaffnit, C., Paradi, J.C., 1998. Marginal rates and two dimensional level curves in DEA. Journal of Productivity Analysis 9 (3), 205232.

Sarrico, C.S., Dyson, R.G., 2004. Restricting virtual weights in data envelopment analysis. European Journal of Operational Research 159 (1), 1734.
Sathye, M., 2001. X efficiency in Australian banking: An empirical investigation. Journal of Banking \& Finance 25, 613630.

Serrano Cinca, C., Mar Molinero, C., Chaparro, F., 2004. Spanish savings banks: A view on intangibles. Knowledge Management Research \& Practice 2, 103117.

Thanassoulis, E., 2000. The use of data envelopment analysis in the regulation of UK water utilities: Water distribution. European Journal of Operational Research 126 (2), 436 453.

Thomson, R.G., Langmeier, L.N., Lee, C.T., Thrall, R.M., 1990. The role of multiplier bounds in efficiency analysis with an application to Kansas farming. Journal of Econometrics 46 (1), 93108 .

Tortosa Ausina, E., 2003. Nontraditional activities and bank efficiency revisited: A distributional analysis for Spanish financial institutions. Journal of Economics and Business 55 (4), 371395.

Tulkens, H., 1993. On FDH efficiency analysis: Some metho dological issues and applications to retail banking, courts, and urban transit. Journal of Productivity Analysis 4 (1 2), 183210.

Wilson, P., 1995. Detecting influential observations in data envelopment analysis. The Journal of Productivity Analysis 6 (1), 2745 .

Worthington, A.C., 1998. Testing the association between production and financial performance: Evidence from a not for profit cooperative setting. Annals of Public and Cooperative Economics 69 (1), 6784.

Worthington, A.C., 2004. Determinants of merger and acquisition activity in Australian cooperative deposit taking institutions. Journal of Business Research 57 (1), 4757. 